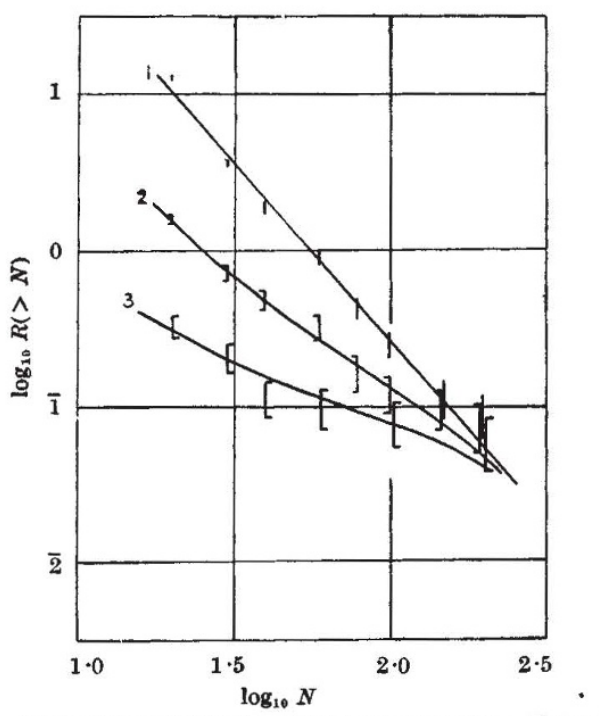

Fig. 3. INTENSITY OF BURSTS. $N$ IS SIZE OF BURST; $R(>N)$ IS RATE/HOUR OF BURSTS OF SIZE GREATER THAN $N$. 1, ALL BURSTS. 2, PenkTRating BURSTs. 3, 'EXTKNSIVE' PENETrating BURSTS

The relation appears to be linear, and on the average one counter is discharged per local burst of 130 rays. The efficiency of collection of the lower tray is about $\frac{1}{8}$, and it therefore appears possible that local bursts contain on the average $3 / 130$, or about $2 \frac{1}{2}$ per cent of mesons, and are apparently caused by mesons.

The extensive penetrating bursts would appear on the average to be associated with the passage of something like eighteen penetrating particles through the lower half of the apparatus.

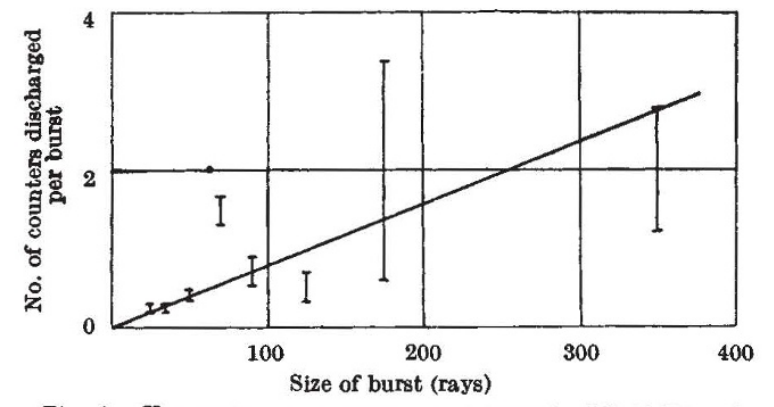

Fig. 4. VARIATION OF NUMBER OF COUN'TERS DISCHARGED BY 'LOCAI PENETRATING BURSTS'

It would appear that additional processes are involved in burst production, under thick lead, over and above the creation of high-energy electrons and photons by mesons, and the subsequent cascade development of the former. For bursts of size greater than 100, these additional processes are involved in a large fraction of bursts, and this would appear to invalidate the arguments put forward for assigning the value 0 to the spin of the cosmic ray meson ${ }^{4}$, based on measurements of burst production under thick materials.

Birkbeck Callege,

University of London. Nov. 12.

1 George and Jánossy, Phys. Rev., 70, 773 (1946).

Jánossy and Broadbent, Proc. Roy. Soc., A, 190, 497 (1947).

George and Jason, see previous communication.

- Christy and Kusaka, Phys. Rev., 59, 414 (1941).

\section{STRUCTURE OF TURNIP YELLOW MOSAIC VIRUS CRYSTALS IN THE ELECTRON MICROSCOPE}

\author{
BY DR. V. E. COSSLETT \\ (I.C.I. Fellow) \\ Cavendish Laboratory, Cambridge \\ AND \\ DR. ROY MARKHAM
}

Plant Virus Unit, Molteno Institute, Cambridge

T $T$ is known from examination in the electron 1 microscope that turnip yellow mosaic virus ${ }^{2}$ consists, in the dry state, of individual particles of spherical form and about $22 \mathrm{~m} \mu$ in diameter. It readily forms macroscopic crystals, usually octahedra, from aqueous salt solutions. Preliminary $\mathrm{X}$-ray studies indicate that these wet crystals have a large unit cell, and Carlisle suggests ${ }^{2}$ that the lattice may be of the diamond type. Attempts have been made to obtain replicas of the dry crystals, by the method which has proved successful with some other plant viruses ${ }^{3,4}$, but these have not shown any regular structure. The failure may be due to the shape of the crystals or to difficulties of drying.

Electron micrographs have been taken (by trans. mission) of the virus mounted on beryllium films, and some of them show a number of micro-crystals having the appearance of a net formed by hexagonal rings (Fig. 1). Each ring has an electron-transparent hole in the centre, of such a size that the rings appear larger than the size of the individual virus particles. From the photographic density of the images, it may be estimated that the crystalline fragments are only a few molecules thick in the direction of the electron beam. The fainter patches in the background also show similar structure in some regions, and may be only two or three molecules deep.

As the electron micrographs seemed to agree with a diamond-type lattice, measurements were made on the hexagonal network in various directions. The

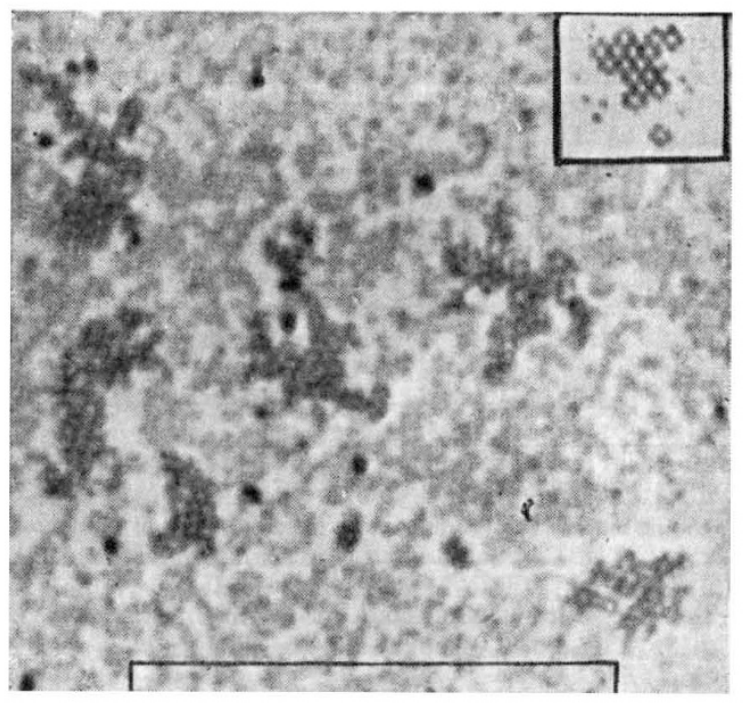

Fig. 1. ELEOTRON MICROGRAPH OF FRAGMENTS OF CRYSTALIINE TURNIP YELLOW MOSAIO VIRUS: PHOTOGRAPHED AT 19,000 $\times$, TOTAL MAGNIFIOATION $48,400 \times$. INSET: OUT-OF-FOOUS PHOTOGRAPH OF MODEL OF DIAMOND LATTIOE 


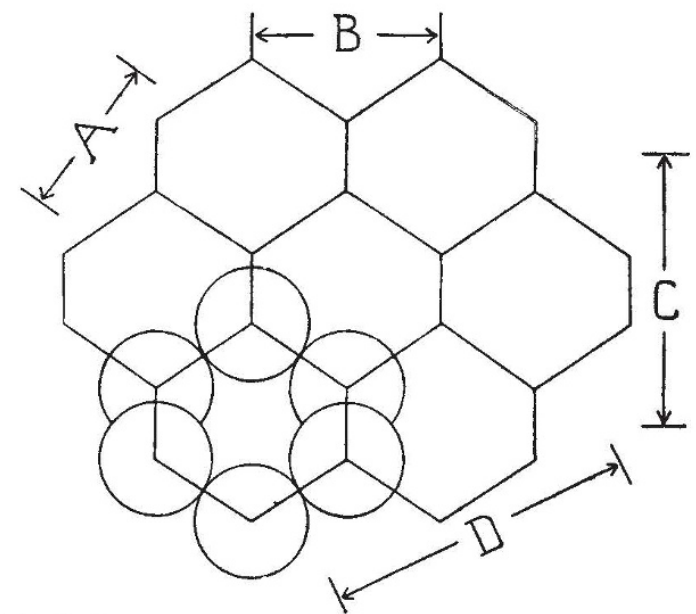

Fig. 2. PROJECTION OF DIAMOND-TYPE LATTICE, VIEWED NORMAL TO 110 FACE

measurements were made easier by the fact that the crystalline regularity extended in places as far as $150 \mathrm{~m} \mu$, although in other places there was obvious distortion. Prints of the negatives were made on process plates, and these were projected at a final magnification of 186,500 times on to paper. The centres of the holes were marked, and measurements made with a ruler, the distances between 146 pairs of holes being measured in all. The measurements were made in four principal directions inclined to each other ( $A, B, C, D$, in Fig. 2), and suggest that the pattern is not a regular hexagonal one, since for the latter $A=B$ and $C=D$. They do, however, agree well with the hypothesis that the crystal is of diamond type, viewed normal to the 110 face, along the diad axis. The measurements are tabulated in Table 1.

\begin{tabular}{ccc}
\multicolumn{3}{c}{ TABLE 1 } \\
Axis & Average distanoe (mm.) & No. of holes measured \\
$A$ & $5 \cdot 18$ & 42 \\
$B$ & $5 \cdot 40$ & 56 \\
$C$ & $8 \cdot 60$ & 35 \\
$D$ & $9 \cdot 67$ & 13
\end{tabular}

From the known relative values for the dimensions $A, B, C$ and $D$, the theoretical spacings fitting the above data were calculated by the least squares method and are given in Table 2 in units of the diameter of the particles composing the lattice, assuming them to be rigid spheres.

$$
\begin{array}{ccc}
\text { TABLE 2 } & \text { Value calculated from } \\
\text { Axis } & \text { Theoretical value } & \begin{array}{c}
\text { experimental data } \\
A
\end{array} \\
A & 1 \cdot 41 & 1 \cdot 44 \\
B & 1.63 & 1 \cdot 50 \\
C & 2 \cdot 31 & 2 \cdot 40 \\
D & 2 \cdot 74 & 2 \cdot 70
\end{array}
$$

A photograph of a model of the diamond lattice, taken out of focus to correspond with the lack of resolution of the electron micrograph, has been superimposed on Fig. 1 in order to give a visual comparison of the observed and postulated structures.

The size of the rigid spherical particle best fitting the data is $19.5 \mathrm{~m} \mu$ in diameter. As the dry virus has a density of $1 \cdot 45$, the molecular weight is about $3.5 \times 10^{6}$. These figures compare with the value of $22 \mathrm{~m} \mu$ for the diameter, obtained from electron micrographs of individual dry particles and by other methods ${ }^{5}$, and with the value of $30 \mathrm{~m} \mu$ suggested by the X-ray evidence and $28 \mathrm{~m} \mu$ from the diffusion constant, the latter two values referring to the particles in the wet state. On the basis of these values, the water content by volume of the crystals would be 84 per cent, compared with 62 per cent for bushy stunt virus crystals. However, the formation of a diamond-type lattice, instead of a close-packed type, by the turnip yellow mosaic virus would indicate the existence of tetrahedrally directed bonding forces between the virus particles. It is therefore possible that in the crystal the particles suffer distortion compared with the spherical form which they probably (although not certainly) have in isolation. Such a change in shape in the lattice would allow a smaller water content than that derived on the assumption of rigid spheres.

The beryllium films were prepared according to the melhod described by Hast ${ }^{B}$. One droplet of the virus suspension in distilled water is placed on a collodion film carried on a nickel specimen grid. After drying, a layer of beryllium approximately $50 \mathrm{~A}$. thick is evaporated on to the surface in a highly evacuated bell-jar. Immersion in pure amyl acetate or acetone dissolves away the underlying collodion, leaving the virus supported by the beryllium alone on the nickel grid. The original micrographs were taken at a magnification of 15,000 .

Attempts to observe similar crystals by drying the virus on pre-formed films of beryllium have so far yielded no unambiguous result, although fragments of the same general shape as shown in Fig. 1 are frequently obtained; they are, however, not resolved into molecular structure. It is probable that the evaporation method of making the beryllium film results in an accentuation of contrast in the specimen, the deposited film having a slightly greater thickness to the beam where it is inclined to the plane of the collodion substrate; a similar effect gives rise to contrast in silica replicas of surfaces. It may also be that beryllium atoms reaching the surface are mobile on it for a short while, and aggregate preferentially along edges. Similar preparations of tomato aucuba mosaic virus show such an accentuation of the sides of rods and rod-aggregates (Fig. 3). When this virus is settled on to preformed beryllium films, however, no

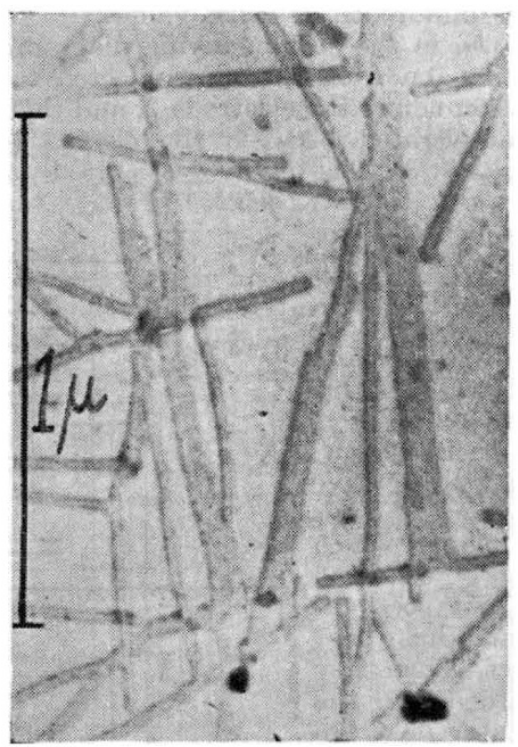

Fig. 3. ELECTRON MiCROGRAPH OF TOMATO AUCUBA MOSAIC (aRAP 
trace is visible of this effect, making it clear that the particles are not hollow in the centre, as might be inferred from Fig. 3.

Beryllium films allow much clearer micrographs to be obtained of virus and similar particles than when they are carried on collodion films, owing to the greater background scattering given by the latter. Particle-size determination is thereby made more accurate, especially when side-by-side aggregations are obtainable, as in Fig. 3. It is observed, however, that the virus exposed to the electron beam rapidly becomes clouded over and all definition is lost in a few minutes. It is probably as much due to this effect as to the greater background scattering, that the lattice structure in crystalline fragments of viruses has not previously been observed with collodion-supported preparations. The nature of this contamination has been discussed elsewhere?

${ }^{1}$ Markham, R., and Smith, K. M., Nature, 157, 300 (1946).

- Carlisle, C. H., private communication.

'Price, W. C., and Wyckoff, R. W. G., Nature, 157, 764 (1946). - Markham, R., Smith, K. M., and Wyckoff, R. W. G., Nature, 159,

- Unpublished data.

- Hast, N., Nature, 159, 354 and 370 (1947).

'Cosslett, V. E., Electron Microscope Conference, Leeds, Sept. 1947, in the press.

\section{DISCHARGE TUBE FOR NUCLEAR REACTIONS WITH IMPROVED YIELD}

$\mathrm{N}$ an article on a "Discharge Tube for Nuclear Reactions with Improved Yield" (Elektrotechnicky Obzor (Prague), 36, No. 14, 266 ; 1947), I have described a new discharge tube which, besides giving a better yield and minimized target heating, has the advantage that the acceleration of the particles is effected in two stages: acceleration by means of 100 $300 \mathrm{kV}$. with a current consumption of the order usual for normal discharge tubes using 1-2 MV., and a following principal acceleration by a tension of some megavolts with a current consumption less than five hundredth of usual values.

As shown in the accompanying diagram, particles leaving the ion source 1 are subjected to the first acceleration before the electrode 2 , and then they are highly accelerated between the electrodes 2, 2"; $2^{\prime \prime}, 2^{\prime \prime \prime} ; 2^{\prime \prime \prime}, 3$. The highly accelerated particles go through the target, which is $5 \times 10^{-4} \mathrm{~cm}$. thick. Only a small number of them produce nuclear reactions or are diverted from their direct paths. Through the scattering by electrons, the other particles give up that part of their kinetic energy which they have obtained by the first acceleration, and thus heat the target. Then they are retarded into the electrostatic field between the electrodes 3,$5 ; 5^{\prime}, 5^{\prime \prime} ; 5^{\prime \prime}, 6$ to such a degree that they enter into the recombination place 6 with little kinetic energy. After recombination, they are sucked from 6 by a high-vacuum pump into a reservoir or through a high-vacuum pipe of sufficient length back into the ion-source 1. The condensers 7 serve to divide the tension. At the same time they hold it constant, as does condenser 8 . The tension for the first acceleration is brought to connectors 9 and that for the chief acceleration to connectors 10.

The greater part of my article relates to the theoretical calculations of the energy conditions in the new tube, and six numerical examples are provided. In order to produce $10^{11}$ neutrons per second from beryllium $5 \times 10^{-4} \mathrm{~cm}$. thick by deuterons, we need for the first acceleration the current-intensity $800 \mu \mathrm{A}$. at a tension of $300 \mathrm{kV}$., and for the chief acceleration $0 \cdot 28 \mu \mathrm{A}$. at $2 \cdot 70 \mathrm{MV}$. If we raise the tension for the chief acceleration to $9.90 \mathrm{MV}$., the current consumption is $0.016 \mu \mathrm{A}$. for the chief acceleration and $800 \mu \mathrm{A}$. at a tension $100 \mathrm{kV}$. for the first acceleration. In the usual discharge tubes with a massive target, we need under the same conditions a current intensity not less than $150 \mu \mathrm{A}$. at $3 \mathrm{MV}$. and not less than I6 $\mu \mathrm{A}$. at $10 \mathrm{MV}$.

Thus the reduction of current consumption for the chief acceleration is very considerable. Also the target heating is minimized. In spite of this, its cooling (by radiation) is the most difficult problem of the new tube. This point will probably decide whether it will be advantageous to construct the tube.

The principal idea of the new tube, namely, to regain the kinetic energy of the highly accelerated particles by means of retardation in the electrostatic field, can be used with great advantage in the construction of other tubes for nuclear physics. In those, and not in the tube discussed, lies the practical use and importance of the scheme.

JARoslav Padhner

\section{WAR-TIME RHEOLOGICAL INVEST- IGATIONS FOR THE BRITISH ARMED SERVICES}

A

GENERAL meeting of the British Rheologists' Club was held at the Royal Society of Arts on December 17, when papers on war-time rheological investigations were read by Dr. A. S. C. Lawrence (Navy). Mr. A. G. Ward (Army) and Dr. E. W. J. Mardles (Royal Air Force). Dr. A. S. C. Lawrence spoke on the experiments done subsequent to the lecture on rheology and Naval problems by Sir Charles Goodeve in 1943 ("Essays in Rheology", Pitman, 1947), and by means of photographs he described the icing of ships in the North Atlantic and methods employed for de-icing. Dr. Lawrence continued with the problem of sea-water - fuel emulsions and fundamental work carried out in connexion with it.

Mr. A. G. Ward spoke on researches carried out with regard to the elasticity and plasticity characteristics of various propellants and of methods of rheological measurement involved, including those of resonance and penetration. Dr. E. W. J. Mardles mentioned rheological problems involved in the highspeed and high-altitude flight of aircraft, when temperatures so low as $-80^{\circ} \mathrm{C}$. are sometimes reached, with consequent development of tendency in 